\title{
Studi Kebutuhan pada Perancangan Mobile Kitchen Truck sebagai Sarana Penunjang Penanggulangan Bencana Daerah Dataran Tinggi
}

\author{
Mohammad Aulia Yustisia Anwar, Bambang Iskandriawan, \\ Ari Dwi Krisbianto, dan Bambang Tristiyono \\ Departemen Desain Produk, Fakultas Desain Kreatif dan Bisnis Digital, \\ Institut Teknologi Sepuluh Nopember, Surabaya, Indonesia \\ e-mail: mohammad.ar06@gmail.com
}

\begin{abstract}
Abstrak-Sebagai negara dengan julukan Ring of Fire membuat sebagian wilayah di Indonesia rawan mengalami bencana alam seperti gunung meletus, banjir bandang, dan kebakaran hutan. Dampak yang dirasakan adalah terganggunya aktifitas primer, kehilangan tempat tinggal hingga sanak saudara, dan kesulitan mendapatkan kebutuhan pokok khususnya makanan. Fasilitas yang diberikan oleh pemerintah khususnya untuk memenuhi kebutuhan makanan sehari-hari adalah dengan pengadaaan truk Dapur Umum Lapangan (Dumlap). Dalam praktiknya, truk ini mengalamani beberapa kendala dalam mengakses daerah terdampak khususnya dataran tinggi. Adapun tujuan dari penelitian ini untuk menjawab kendala yang dialami seperti kurang memadainya spesifikasi mesin produk eksisting, dimensi kendaraan yang perlu disesuaikan dengan karakteristik dataran tinggi, dan rancang bangun truk yang kurang efektif. Metode penelitian yang digunakan adalah pertama dengan breakdown masalah dan kebutuhan, preview produk eksisting dan produk acuan, observasi lapangan untuk menentukan Design Requirement \& Objective, wawancara, hingga studi model.
\end{abstract}

Kata kunci- studi kebutuhan, dapur umum lapangan, mobile kitchen truck, dataran tinggi, bencana alam.

\begin{abstract}
As a country with the predicated of the Ring of Fire, several areas in Indonesia are vulnerable to natural disasters such as volcanic eruptions, floods, and forest fires. The impact that is felt is disruption of primary activities, loss of residence to relatives, and difficulties in getting necessities, especially food. The facilities provided by the government, especially to meet daily food needs, are the provision of trucks for the Field Public Kitchen (Dumlap). In practice, this truck has experienced several obstacles in accessing the affected areas, especially the highlands. The purpose of this research is to answer the problems experienced, such as inadequate specifications for existing product machines, Vehicle dimensions that must be adapted to the highlands particularities, and ineffective truck design. The research method used is the first with a breakdown of problems and needs, previews of existing products and reference products, field observations to determine Design Requirements \& Objectives, interviews, to model studies.
\end{abstract}

Keywords—need study, field public kitchen, mobile kitchen truck, highlands. natural disasters.

\section{PENDAHULUAN}

Berdasarkan sudut pandang geografis, Indonesia merupakan pertemuan dua jalur gunung api besar dengan beberapa jalur pegunungan lipatan muda dunia. hal tersebut terjadi karena pertemuan tiga lempeng tektonik dunia, yaitu lempeng IndoAustralia, Eurasia dan lempeng Pasifik. Aktivitas tektonik tersebut memicu terbentuknya jajaran gunung berapi aktif (volcanic arc) yang sering disebut Ring of Fire [1].

Kondisi tersebut membuat banyak daerah di Indonesia rawan terhadap bencana alam. Badan Daerah Penanggulangan Bencana (BPBD) mencatat tren kebencanaan yang terjadi di Indonesia dalam kurun waktu 10 tahun terakhir [2].

Bencana alam sendiri dapat berdampak terhadap timbulnya korban jiwa, kerusakan lingkungan, kerugian materiil, serta dampak psikologis [3]. Bagi masyarakat yang terdampak bencana alam, sandang, pandang, dan papan menjadi kebutuhan dasar yang harus dipenuhi agar tetep bisa bertahan dalam kondisi sulit. Bencana alam tertentu dapat berdampak pada kebutuhan sandang atau pakaian yang rusak, hilang, atau tidak layak pakai. Selain itu, kebutuhan pangan atau makanan juga diperlukan karena keterbatasan masyarakat terdampak untuk mendapatkan dan mengolah bahan pangan. Bencana alam juga dapat berdampak pada kebutuhan akan papan atau tempat tinggal. Bagi masyarakat yang mengalami bencana alam seperti banjir, erupsi gunung merapi, atau angin puting beliung mengakibatkan rumah mereka tidak dapat ditinggali untuk karena rusak atau bahkan roboh.

Penelitian ini menggunakan studi kasus bencana di Kecamatan Ijen, Bondowoso. Daerah ini memiliki karakteristik dataran tinggi karena dikelilingi oleh beberapa gunung seperti seperti G. Suket (2.950 mdpl), G. Raung (3.334 mdpl), G. Pendil (2.338 mdpl), G. Rante (2.664 mdpl), G. Merapi (2.800 mdpl), G. Remuk (2.092 mdpl), dan G. Ijen (2.799 mdpl) [4]. Berada di lereng pegununan Ijen dan dikelilingi oleh dua gunung berapi aktif yaitu Gunung Ijen dan Gunung Raung menjadikan daerah tersebut termasuk dalam daerah rawan terdampak bencana. Tercatat ada beberapa bencana alam yang pernah melanda daerah tersebut beberapa tahun terakhir antara lain erupsi gunung raung (2015), kebakaran hutan (2019), dan banjir bandang (2020).

Saat terjadi bencana alam, terdapat dua instansi terkait dalam proses penanggulangannya yaitu Dinas Sosial dan BPBD. Dalam tahap sistem tanggap darurat, Dinas Sosial bertugas sebagai aktivasi tanggap darurat (dapur umum, tenda pengungsian dan pemenuhan logistik); posko layanan dukungan psikososial; pengerahan relawan Taruna Siaga Bencana (Tagana) dan relawan sosial lain; penyaluran bantuan untuk memenuhi kebutuhan dasar dan pelayanan khusus terhadap kelompok rentan [5]. 
Sedangkan BPBD memiliki tugas pada saat tanggap darurat dalam hal penanganan korban di lapangan, tambahan kebutuhan logistik, koordinator dan pelaksana kebijakan di bidang penanggulangan bencana [6].

Tentunya dampak dari bencana alam dapat diminimalisir dengan pemberian bantuan maupun pertolongan baik dari pihak pemerintah maupun dari sukarelawan. Menurut Dinas Sosial Kab. Buleleng terdapat beberapa jenis bantuan/pertolongan yang dapat diberikan kepada masyarakat terdampak bencana alam seperti: 1. Bantuan Relokasi Sementara; 2. Bantuan Kebutuhan Pokok; 3. Bantuan Peralatan Darurat [7].

Salah satu kebutuhan masyarakat terdampak yang harus terpenuhi adalah makanan pokok. Fasilitas yang diberikan pemerintah berkaitan dengan makanan pokok sehari-hari dalah truk Dapur Umum Lapangan (Dumlap). Seperti dapat dilihat pada Gambar 1.

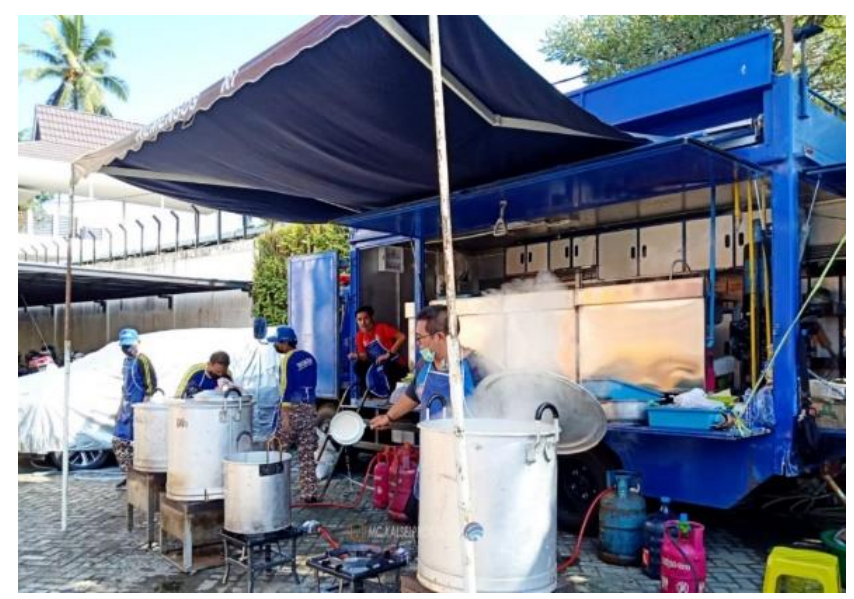

Gambar 1. Truk Dapur Umum

Adapun tugas pokok meliputi kegiatan penanggulangan pasca bencana khususnya dalam kegiatan pemenuhan kebutuhan makan sehari-hari para korban bencana alam/sosial dilokasi bencana. Dapur umum lapangan mampu memproduksi hingga 2.000 porsi makanan dalam sekali masak [8].

Sebagai daerah dataran tinggi yang memiliki karakteristik tanah yang berbukit, minim akses, dan sebagian besar hutan menjadikan kendala tersendiri pada proses penyaluran bantuan saat terjadi bencana alam. Selain itu diskoordinasi, keterlambatan transportasi dan distribusi, serta ketidaksiapan lokal dalam pemenuhan sarana dan prasarana menjadi masalah tersendiri dalam praktik di lapangan [9].

Kebutuhan pokok yang perlu dipenuhi adalah makanan sehari-hari. Dalam proses distribusi, diperlukan moda transportasi yang siap memobilisasi kebutuhan tersebut. Ditambah dengan kondisi bencana alam yang terjadi di daerah dataran tinggi, maka kendaraan yang digunakan harus mampu berjalan disegala medan, memiliki fitur pendukung, dan manajemen dapur umum yang baik. Karena desain dan karakter suatu produk adalah salah satu tolak ukur bagi keberhasilan pada perancangan sebuah produk [10] dan [11].

\section{METODE PENELITIAN}

Secara umum, metode penelitian yang dilakukan penulis dengan proses pengumpulan data (primer dan sekunder), data yang didapat kemudian dianalisis, yang selanjutnya menghasilkan beberapa kesimpulan.

\section{Data primer}

Data primer diperoleh dari hasil wawancara secara langsung dengan beberapa narasumber yang berasal dari pihak petugas lapangan, warga terdampak, dan juga dari pihak stakeholer.

Wawancara pertama dilakukan bersama Sony (30th) yang bekerja sebagai Kordinator Lapangan Dapur Umum Bencana Alam. Wawancana ini dilakukan pada tanggal 23 Maret 2021 dan membahas tentang manajemen dapur umum lapangan bencana.

Wawancara kedua dilakukan bersama Okta (30th) yang berprofesi sebagai pengusaha kopi sekaligus masyarakat lokal kec. Ijen. Wawancara dilakukan pada tanggal 15 Maret 2021 dan membahasa tentang kondisi lapangan saat terjadi bencana alam.

Wawancara ketiga dilakukan bersama Redi (55th) yang bekerja sebagai Kepala Bidang Penanggulangan Bencana, Dinas Sosial Kab. Bondowoso. Wawancana ini dilakukan pada tanggal 23 Maret 2021 dan membahas tentang alur kordinasi penanggulangan bencana, SOP, dan kondisi eksisting truk dapur umum lapangan.

Selain mengambil data dengan wawancara, penulis juga melakukan studi lapangan di daerah terdampak bencana alam tepatnya di Kecamatan Ijen, Kabupaten Bondowoso, Jawa Timur (Gambar 2).

\section{Data sekunder}

Data sekunder merupakan data yang diperoleh secara tidak langsung, baik itu melalui buku, jurnal hasil penelitian, maupun dokumen lainnya.

\section{HASIL DAN PEMBAHASAN}

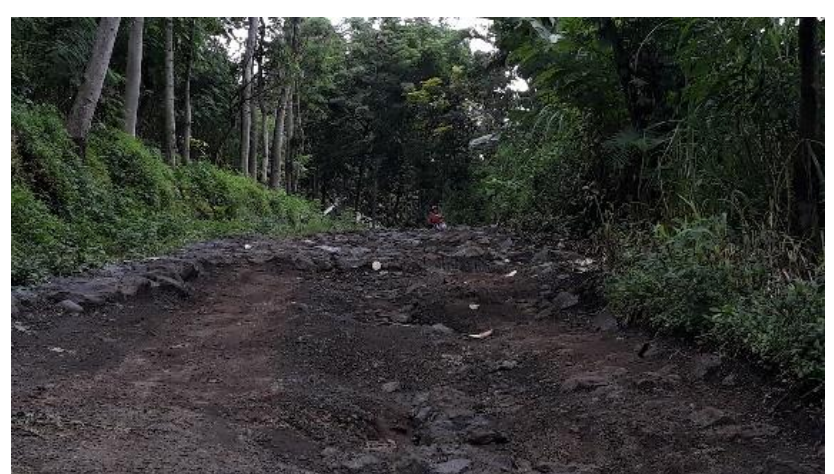

Gambar 2. Akses menuju salah satu dusun terdampak banjir bandang Ijen.

\section{Pembahasan data primer}

Data primer yang diperoleh penulis kemudian diolah untuk mendapatkan studi masalah, studi kebutuhan, dan analisis geografis. Adapaun pembahasannya adalah sebagai berikut:

\section{Studi masalah:}

1. Dataran tinggi ditambah dengan keterbatasan akses di lokasi menjadi masalah dalam hal mobilisasi bencana alam.

2. Keterbatasan space untuk operasional dapur umum lapangan mengingat karakteristik daerah berada di dataran tinggi.

3. Volume truk dapur umum lapangan belum bisa mengakomodir kebutuhan memasak dalam skala masif. 


\section{Studi kebutuhan sebagai solusi:}

1. Dibutuhkan moda transportasi yang mampu mengakomodir mobilisasi di daerah dataran tinggi yang minim akses.

2. Konfigurasi dapur umum lapangan yang mampu digunakan dalam kondisi space terbatas.

3. Optimalisasi tata letak kompartemen sesuai kebutuhan di lapangan

\section{Pembahasan data sekunder}

Data sekunder yang telah dikumpulkan selanjutnya digunakan untuk menentukan alur aktifitas, barang bawaan, dan klasifikasi bencana alam. Adapun alur aktifitas dibagi menjadi dua: didalam truk dan diluar truk.

Pada saat petugas melakukan kegiatan yang berkaitan dengan meracik, memasak, dan membersihkan peralatan, alur aktivitas memasak secara umum dapt dilihat pada Gambar 3.

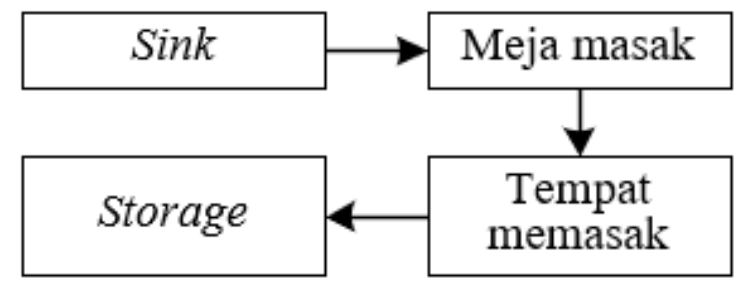

Gambar 3. Alur aktivitas memasak petugas secara umum.

Selanjutnya alur ini dijadikan acuan dalam positioning konfigurasi. Sedangkan diluar aktivitas yang berkaitan dengan mobilisasi mulai dari dinas sosial hingga menuju lokasi kejadian, dan juga melakukan set up dasar dapur umum seperti membuka kanopi.

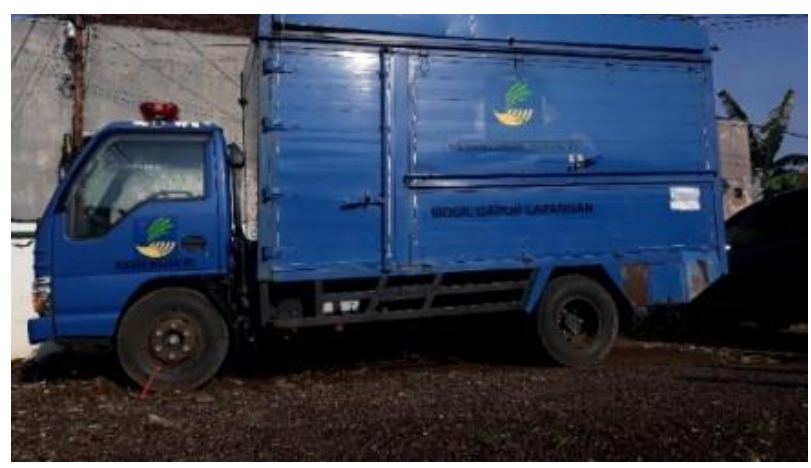

Gambar 4. Truk Dapur Umum Lapangan Kemensos sebagai produk eksisting

\section{Konsep desain}

Berdasarkan data primer dan sekunder yang telah didapat dan diolah kemudian menghasilkan konsep desain sebagai berikut:

1. Accessibility

Kendaraan dapat dioperasionalkan di berbagai medan khususnya daerah dataran tinggi dengan kontur jalan bergelombang dan tidak rata. Serta dilengkapi teknologi tambahan yang mampu menunjang area terdampak bencana alam.

2. Efectivity

Efektifitas ruang. Dapur umum yang digunakan mampu memaksimalkan ruang yang tersedia dengan kondisi dan karakteristik bencana alam di daerah dataran tinggi.

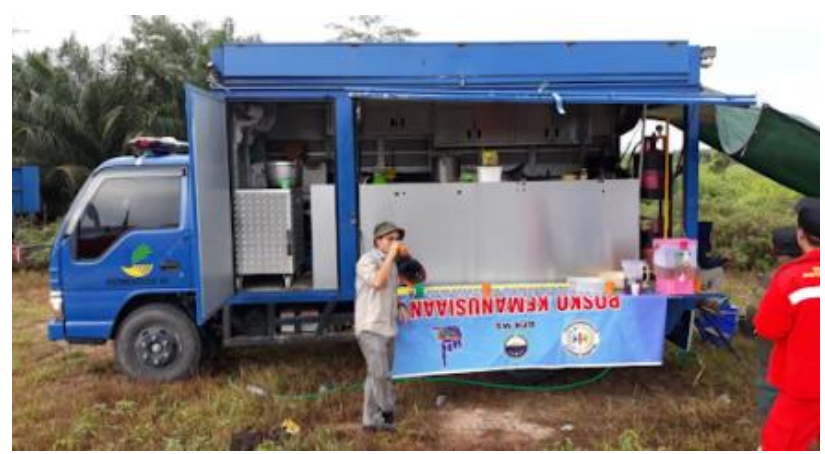

Gambar 5. Box Dapur Umum Lapangan dalam kondisi terbuka. Sumber: http://ditjenppi.menlhk.go.id/

Tabel 1 menjelaskan spesifikasi kendaraan truk eksisting. Sedangkan Tabel 2 spesifikasi Box Dapur umum.

Tabel 1. Spesifikasi kendaraan truk eksisting sebagai acuan pengembangan desain.

\begin{tabular}{|l|l|}
\multicolumn{2}{|c|}{ Sengembangan desain. } \\
\hline Merk Type & Isuzu (NKR 71 HD E2-2) \\
\hline Jenis Model & $\begin{array}{l}\text { Mobil Barang Del Van } \\
\text { (BSWG) }\end{array}$ \\
\hline Isi Silinder & 4670 \\
\hline \multicolumn{1}{|c|}{ Dimensi } \\
\hline Jarak Sumbu Roda & $3360 \mathrm{~mm}$ \\
\hline Panjang Keseluruhan & $1920 \mathrm{~mm}$ \\
\hline Tinggi Keseluruhan & $2120 \mathrm{~mm}$ \\
\hline Ground Clearance & $210 \mathrm{~mm}$ \\
\hline Jarak Pijak Roda Depan & $1408 \mathrm{~mm}$ \\
\hline Jarak Pijak Roda Belakang & $1425 \mathrm{~mm}$ \\
\hline \multicolumn{2}{|c|}{ Kemampuan } \\
\hline Radius Putar & $7.5 \mathrm{~m}$ \\
\hline Daya & $125 \mathrm{PS} \mathrm{/} \mathrm{2900} \mathrm{rpm}$ \\
\hline Torsi & $35 \mathrm{Kgm} / 1200-2200 \mathrm{rpm}$ \\
\hline Daya Tanjakan & $45 \%$ \\
\hline Daya Angkut & $5847 \mathrm{~kg}$ \\
\hline \multicolumn{2}{|c|}{ Roda } \\
\hline Depan & $7.50-16-14 \mathrm{PR}$ \\
\hline Belakang & Double 7.50-16-14PR \\
\hline Jumlah Baut per Roda & 6 Buah \\
\hline \multicolumn{2}{|c|}{ Transmisi } \\
\hline Tipe & 5 gigi maju dan 1 gigi mundur \\
\hline
\end{tabular}

Tabel 2. Spesifikasi box dapur umum sebagai studi awal perancangan.

\begin{tabular}{|l|c|}
\hline \multicolumn{2}{|c|}{ Spesifikasi Box Dapur Umum } \\
\hline Ukuran (pxlxt) & $4300 \mathrm{~mm} \times 2000 \mathrm{~mm} \times$ \\
& $1800 \mathrm{~mm}$ \\
\hline Lantai & Aluminium (3mm) \\
\hline Dinding Luar & Aluminium $(1.5 \mathrm{~mm})$ \\
\hline Dinding kiri & $-2 / 3$ buka atas dengan \\
& penahan hidrolik \\
& $-1 / 3$ buka bawah dengan \\
& penahan rantai/siku \\
\hline Penerangan & 5 unit 24V 10W \\
\hline Tangki Air & $700 l$ \\
\hline
\end{tabular}

Efektifitas waktu. Truk dapur umum bencana dapat memaksimalkan waktu tempuh dari lokasi awal (kantor Dinas Sosial/BPBD) menuju lokasi bencana. Selain itu efektifitas waktu dari segi operasional dapur umum saat digunakan di lapangan.

\section{Studi platform kendaraan}

Studi ini bertujuan untuk mengetahui platform yang akan digunakan berdasarkan produk truk eksisting. Studi ini berkaitan dengan spesifikasi kendaraan berbasis truk dan 
juga box dapur umum yang menjadi salah satu objek penelitian (Gambar-gambar 4 dan 5).

\section{Analisis barang bawaan}

Dibedakan berdasarkan zonasi kegiatan yang ada pada dapur umum, seperti zona persiapan dan pembersihan, zona meracik, dan zona memasak. Adapun barang bawaan (equipment) dapat dilihat pada Tabel 3.

\section{Analisis kalkulasi porsi makanan}

Tujuan dari studi ini untuk mengetahui perhitungan kebutuhan porsi dengan ketersediaan alat dan ruang. Menurut bapak Sony selaku kordinator truk dapur umum lapangan dengan menggunakan asumsi 1000 korban terdampak menghasilkan perhitungan seperti dapat dilihat pada Gambar 6.

\begin{tabular}{|c|c|}
\hline Barang & Dimensi $(\mathrm{mm})$ \\
\hline \multicolumn{2}{|c|}{ Zona Persiapan dan Pembersihan } \\
\hline Freezer 200lt & $950 \times 580 \times 850$ \\
\hline Big Wall Mounted Cabinet & $1800 \times 350 \times 500$ \\
\hline Swing Cabinet & $1800 \times 400 \times 850$ \\
\hline Small Wall Mounted Cabinet & $1200 \times 300 \times 350$ \\
\hline Single Bowl Sink & $1000 \times 500 \times 850$ \\
\hline \multicolumn{2}{|l|}{ Zona Meracik } \\
\hline Work Table & $1300 \times 600 \times 850$ \\
\hline \multicolumn{2}{|l|}{ Zona Memasak } \\
\hline Gas Stove & $1300 \times 600 \times 850$ \\
\hline
\end{tabular}

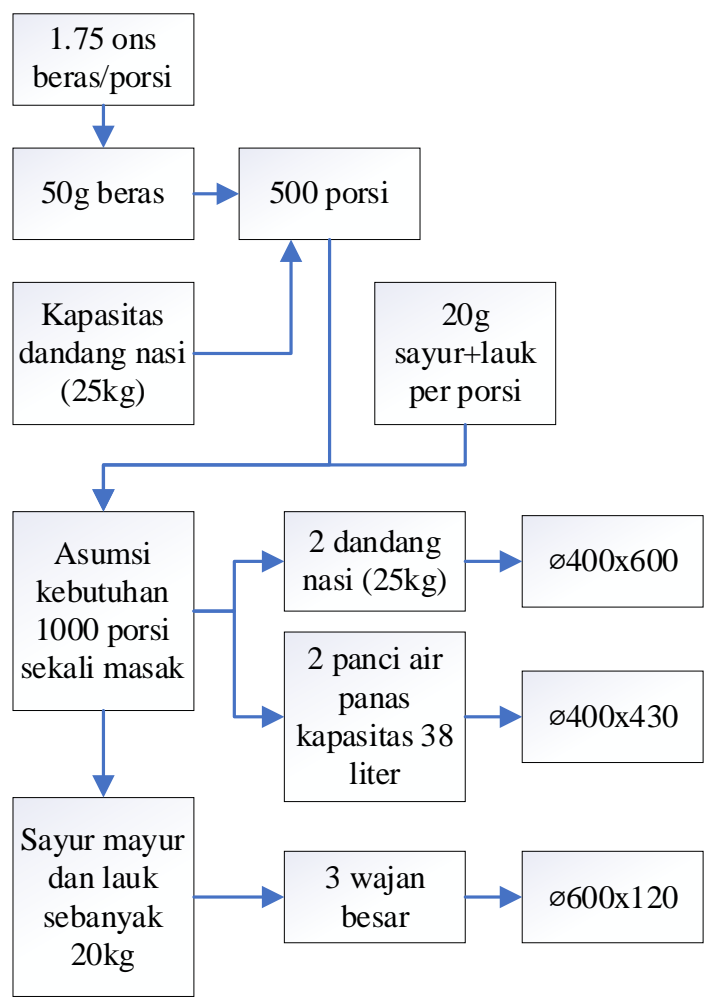

Gambar 6. Truk Dapur Umum Lapangan Kemensos sebagai produk eksisting.

Berdasarkan studi analisa kebutuhan porsi makanan maka dapat disimpulkan bahwa untuk 1000 porsi makanan dibutuhkan 2 dandang nasi kapasitas $25 \mathrm{~kg}$ beras dan tambahan 2 panci dengan kapasitas 38 liter air dalam sekali masak. Sedangkan untuk $20 \mathrm{~kg}$ sayur mayur dan lauk pauk dibutuhkan 3 wajan besar dengan diameter $62 \mathrm{~cm}$.

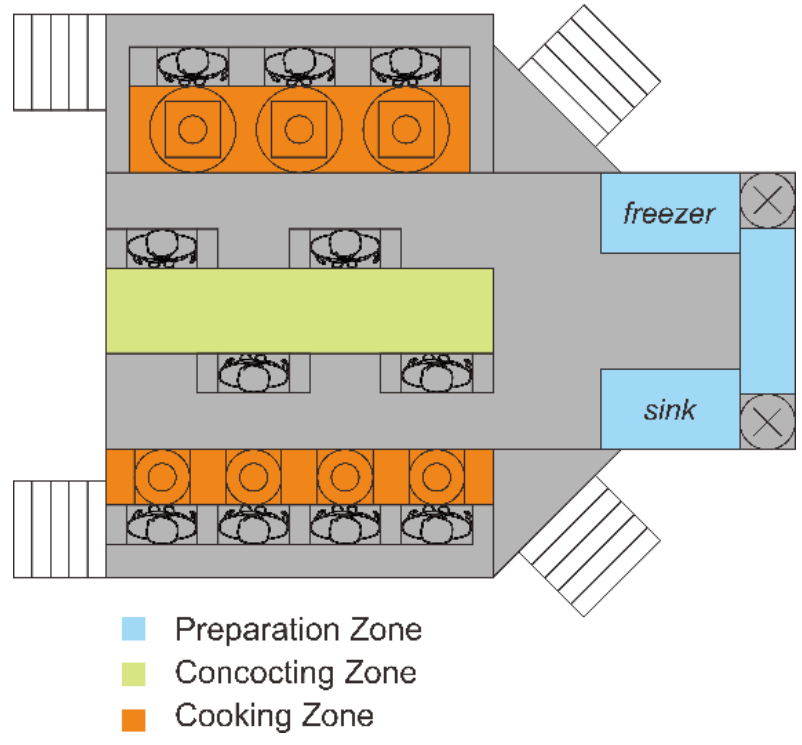

Gambar 7 Alternatif Konfigurasi 1.

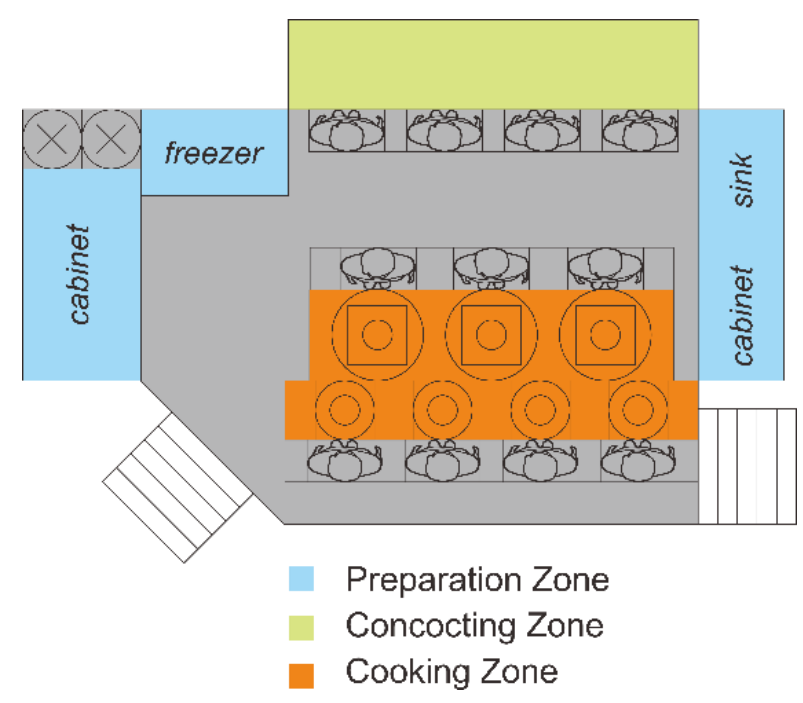

Gambar 8 Alternatif Konfigurasi 2.

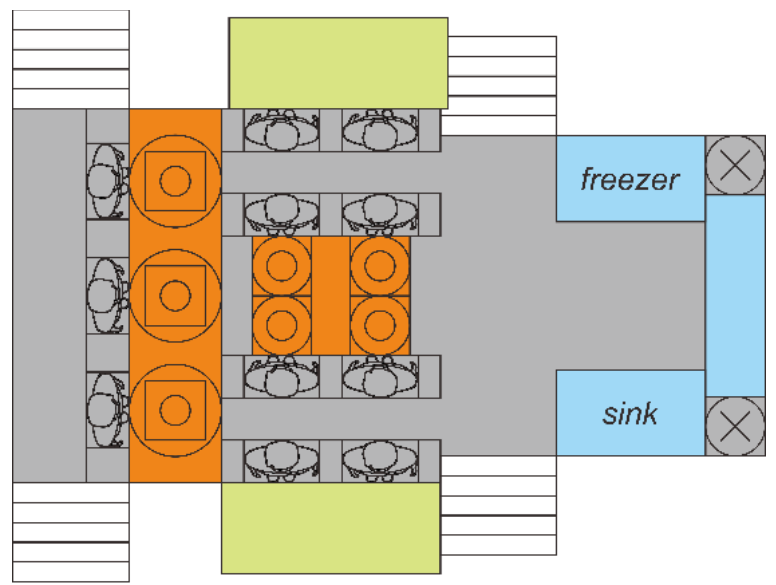

Preparation Zone

Concocting Zone

Cooking Zone

Gambar 9 Alternatif Konfigurasi 3. 
Mohammad Aulia Yustisia Anwar, Bambang Iskandriawan, Ari Dwi Krisbianto, dan Bambang Tristiyono

Studi Kebutuhan pada Perancangan Mobile Kitchen Truck sebagai Sarana Penunjang Penanggulangan Bencana Daerah

Dataran Tinggi

\section{Analisis konfigurasi}

Analisa akses pengguna bertujuan untuk menentukan konfigurasi dan tata letak dapur umum lapangan yang paling optimal bagi truk dapur umum lapangan. Analisis ini kemudian menghasilkan alternatif konfigurasi yang disesuaikan dengan barang bawaan dan urutan aktivtias pengguna.

Adapaun alternatif konfigurasi truk dapur umum lapangan adalah sebagai berikut dapat dilihat pada Gambar-gambar 7, 8 , dan 9.

\section{KESIMPULAN}

Studi kebutuhan pada perancangan mobile kitchen truck sebagai sarana penunjang penanggulangan bencana daerah dataran tinggi memiliki beberapa hal yang perlu dipertimbangkan. Spesifikasi teknis kendaraan yang akan digunakan dapat dilihat pada Tabel 4.

Tabel 4. Spesifikasi kendaraan truk yang dipilih.

\begin{tabular}{|l|l|}
\hline \multicolumn{2}{|c|}{ Spesifikasi Kendaraan } \\
\hline Merk Type & Isuzu (NKR 71 HD E2-2) \\
\hline \multicolumn{2}{|c|}{ Dimensi } \\
\hline Wheelbase & $3360 \mathrm{~mm}$ \\
\hline Panjang Keseluruhan & $1920 \mathrm{~mm}$ \\
\hline Tinggi Keseluruhan & $2120 \mathrm{~mm}$ \\
\hline Ground Clearance & $210 \mathrm{~mm}$ \\
\hline
\end{tabular}

Adapun aspek penentu tersebut dirumuskan pada Design Requirement \& Objectives (DR\&O) sebagai berikut:

1. Kendaraan mampu melewati kontur jalanan dengan karakteristik dataran tinggi.

2. Kendaraan mampu melewati daerah terdampak bencana.

3. Dapur umum dapat diperasikan di berbagai medan.

4. Petugas dapat mengoperasionalkan kendaraan maupun dapur umum secara cepat dan tepat.

5. Produk terbuat dari material yang aman, ringan, dan tahan lama.
6. Kompartemen yang berkaitan dengan masak-memasak menggunakan material yang higienis.

7. Produk memiliki konfigurasi yang efektif dan efisien.

8. Memperhatikan citra stakeholder terkait dalam proses desain eksterior dan interior produk.

\section{DAFTAR PUSTAKA}

[1] d. Amri M. R., "RISIKO BENCANA INDONESIA," BNPB, Jakarta, 2016.

[2] C. M., "Apa Bencana Alam yang Paling Sering Terjadi di Indonesia 10 Tahun Terakhir?," 22 September 2020. [Online]. Available: https://databoks.katadata.co.id/datapublish/2020/09/22/apa-bencanaalam-yang-paling-sering-terjadi-di-indonesia-10-tahun-terakhir. [Accessed 23 March 2021].

[3] BNPB, "BNPB," 14 Januari 2013. [Online]. Available: https://bnpb.go.id/definisi-bencana. [Accessed 23 March 2021].

[4] A. F. Hidayanto, "DESAIN DAPUR UMUM," Simposium Nasional RAPI XIII , Samarinda, 2014

[5] K. Setiawan, "Komisi VIII Dukung Langkah Kemensos dalam Penanganan Bencana," Kementrian Sosial, 16 March 2021. [Online]. Available: https://kemensos.go.id/ar/komisi-viii-dukung-langkahkemensos-dalam-penanganan-bencana. [Accessed 12 July 2021].

[6] K. Bogor, "Struktur, Tugas dan Fungsi BPBD," [Online]. Available: https://www.google.com/search?q=tugas+bpbd+saat+bencana\&sxsrf =ALeKk00E8O4GNTKH3Lf1TXsyNvadbjPFXA\%3A16261909529 93\&ei=aLTtYPGOPK6C4t4Pg92osAs\&oq=tugas+bp+saat+bencana \&gs_lcp=Cgdnd3Mtd216EAMYADIECAAQEzoHCCMQsAMQJzo HCAAQRxCwAzoICAAQCBAHEB5KBAhBGABQuRBY3hJguiR . [Accessed 12 July 2021].

[7] S. K. Buleleng, "Dinas Sosial Kab. Buleleng," Dinas Sosial Kab. Buleleng, Buleleng, 2013.

[8] Riana, "Kemensos Bangun 6 Posko Dapur Umum untuk Korban Gempa Majene - Mamuju," 17 Januari 2021. [Online]. Available: https://nasional.tempo.co/read/1424110/kemensos-bangun-6-poskodapur-umum-untuk-korban-gempa-majene-mamuju. [Accessed 12 July 2021].

[9] M. d. Dr. Lucky Tjahjono, "Pedoman Teknis Penanggulangan Krisis Kesehatan Akibat Bencana," Departemen Kesehatan RI, Jakarta, 2007.

[10] Kurniawan, B. D., \& Tristiyono, B. (2019). Studi kebutuhan desain berdasarkan riset konsumen pada produk tas sekolah siswa sma dalam rangka menentukan design requirement and objective (DR\&O). Jurnal Sains dan Seni ITS, 8(1), 34-39.

[11] Sony, Interviewer, Manajemen Mobil Dapur Umum Lapangan. [Interview]. 25 March 2021. 